\title{
Design of Two RadWorks Storm Shelters for Solar Particle Event Shielding
}

\author{
Matthew Simon, Jeffrey Cerro, Kara Latorella, Martha Clowdsley, Judith Watson, Cindy Albertson, Ryan Norman, \\ Vincent Le Boffe \\ NASA Langley Research Center, Hampton, VA, 23681, USA \\ Steven Walker \\ Old Dominion University, Hampton, VA, 23681, USA
}

\begin{abstract}
In order to enable long-duration human exploration beyond low-Earth orbit, the risks associated with exposure of astronaut crews to space radiation must be mitigated with practical and affordable solutions. The space radiation environment beyond the magnetosphere is primarily a combination of two types of radiation: galactic cosmic rays (GCR) and solar particle events (SPE). While mitigating GCR exposure remains an open issue, reducing astronaut exposure to SPEs is achievable through material shielding because they are made up primarily of medium-energy protons. In order to ensure astronaut safety for long durations beyond low-Earth orbit, SPE radiation exposure must be mitigated. However, the increasingly demanding spacecraft propulsive performance for these ambitious missions requires minimal mass and volume radiation shielding solutions which leverage available multi-functional habitat structures and logistics as much as possible. This paper describes the efforts of NASA's RadWorks Advanced Exploration Systems (AES) Project to design two minimal mass SPE radiation shelter concepts leveraging available resources: one based upon reconfiguring habitat interiors to create a centralized protection area and one based upon augmenting individual crew quarters with waterwalls and logistics. Discussion items include the design features of the concepts, a radiation analysis of their implementations, an assessment of the parasitic mass of each concept, and the result of a human in the loop evaluation performed to drive out design and operational issues.
\end{abstract}

\section{Nomenclature}

\section{Acronyms}

$\begin{array}{ll}\text { ACS } & =\text { Attitude Control System } \\ A E S & =\text { Advanced Exploration Systems } \\ A L A R A & =\text { As Low As Reasonably Achievable } \\ A M & =\text { Augmentation Module } \\ B E O & =\text { Beyond Earth Orbit } \\ C A D & =\text { Computer-Aided Design } \\ C L S & =\text { Cislunar Spacecraft } \\ C Q & =\text { Crew Quarter } \\ C P C & =\text { Common Protection Container } \\ C T B & =\text { Cargo Transfer Bag } \\ D S H & =\text { Deep Space Habitat } \\ E C L S S & =\text { Environmental Control and Life } \\ & \text { Support } \\ E M S & =\text { Emission of Solar Protons } \\ E V A & =\text { Extra Vehicular Activity } \\ E X A M I N E & =\text { Exploration Architecture Model for } \\ F A X & =\text { Female Adult voXel } \\ F S P & =\text { Food Storage Pouch } \\ F Y & =\text { Fiscal Year }\end{array}$

\begin{tabular}{|c|c|c|}
\hline$G C R$ & $=$ & Galactic Cosmic Ray \\
\hline GOES & $=$ & Geostationary Satellite \\
\hline$H A L$ & $=$ & Habitable Airlock \\
\hline HAT & $=$ & Human Spaceflight Architecture Team \\
\hline$H D U$ & $=$ & Habitat Demonstration Unit \\
\hline$H M C$ & $=$ & Heat Melt Compactor \\
\hline HZETRN & $=$ & $\begin{array}{l}\text { High charge (Z) and Energy } \\
\text { TRaNsport code }\end{array}$ \\
\hline ICWC & $=$ & Iodinated Contingency Water Canister \\
\hline$I M P$ & $=$ & Interplanetary Monitoring Platform \\
\hline ISS & $=$ & International Space Station \\
\hline$K P P$ & $=$ & Key Performance Parameter \\
\hline LEO & $=$ & Low Earth Orbit \\
\hline$M P C V$ & $=$ & Multipurpose Crew Vehicle \\
\hline$M P L M$ & $=$ & Multipurpose Logistics Module \\
\hline OLTARIS & $=$ & $\begin{array}{l}\text { On-Line Tool for the Assessment of } \\
\text { Radiation in Space }\end{array}$ \\
\hline$P D F$ & $=$ & Probability Density Function \\
\hline$P E D$ & $=$ & Positive Expulsion Device \\
\hline PWD & $=$ & Potable Water Dispenser \\
\hline
\end{tabular}




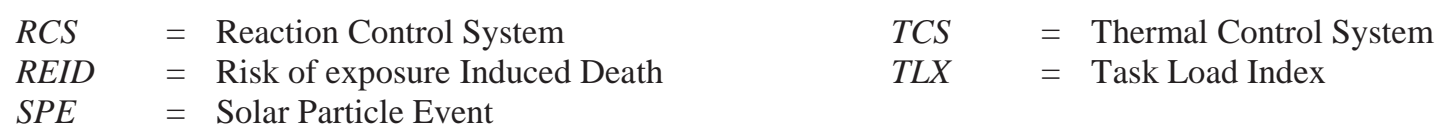

\section{Introduction}

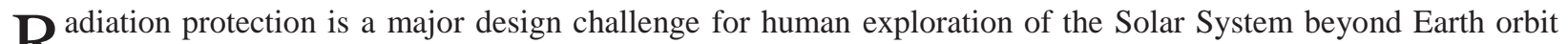
(BEO). Exposure of astronaut crews to the deep space radiation environments increase the risk of deleterious physiological effects such as radiation sickness and late-term effects such as central nervous system damage and increased incidence of debilitating or fatal cancers. Current design and operational strategies for mitigating radiation-related risks focus on the addition of "shielding" to spacecraft designs to protect the crew directly. NASA's RadWorks Advanced Exploration Systems (AES) Project Storm Shelter Team seeks to develop a Solar Particle Event (SPE) radiation storm shelter which leverages the design of multi-functional habitat structures and logistics to minimize radiation shielding mass at launch.

Solar particle events are rare, short-lived (durations are measured in hours), high-exposure rate events. The exposures for these events are higher beyond Earth's magnetosphere. Fortunately, shielding materials (particularly those with high concentrations of hydrogen such as polyethylene and water) are effective at reducing astronaut exposure to these events because SPEs are made up primarily of low and medium energy protons. Therefore, if adequate shielding is provided and astronauts receive sufficient warning to enter the sheltered area, the SPE risk can be managed through appropriate vehicle design.

Adequate shielding could be provided by simply surrounding a vehicle with a large enough mass. However, it is cost prohibitive to launch the mass necessary to shield an entire space habitat. It is also undesirable to carry single-purpose shielding mass dedicated only to provide radiation shielding (i.e. parasitic mass) when logistics and subsystems necessary to support humans can provide sufficient shielding. To address this design problem, the objective of the Radworks Storm Shelter is to design low parasitic mass, temporary SPE shelter concepts which reconfigure, redeploy, and/or reuse available logistics and subsystems to shield smaller areas within a habitat when an SPE occurs. The production of integrated shielding concepts with minimized system impact will feed into the specification of a Concept of Operations for managing the crew SPE exposures for exploration missions. The design effort will also provide valuable insight into how truly integrated vehicle designs can contribute to the mitigation of the unshieldable Galactic Cosmic Rays (GCR).

This paper describes the continuing efforts of the RadWorks Storm Shelter team to analyze and evaluate leading candidates for these SPE shelters and improve them through the creation of subscale and full-scale demonstration articles (see Ref. 1 for more details on previous efforts). Section II describes the two concepts which were evaluated in FY'13, and Section III describes the notional mission and habitation concept used to evaluate them. Section IV outlines the radiation analysis used to determine the amount of shielding necessary for each shelter concept. Section $\mathrm{V}$ describes the deployment operations testing effort which helped to refine design features of the shelter concepts and validate deployment training and timelines. Finally Section VI outlines the conclusions from the study and the future work planned for FY'14.

\section{Concept Definition}

The two leading low-mass, SPE shelter concepts analyzed in Ref. 1 were investigated in greater detail. The first concept featured a single, quickly fabricated enclosure designed to protect the all crewmembers together within a centralized interior habitat location. This central location is advantageous because it leverages the location of systems and goods placed against habitat walls to provide considerable amounts of inherent SPE dose reduction. Building an SPE shelter inside of this moderately sheltering hardware provides a temporary shelter with substantially enhanced protection. In order to further minimize the mass impact to the habitat system, logistics stored in an alternate location distant from the sheltered region are utilized as the primary construction materials. This dependence on logistics placement and repackaging of some logistics throughout their lifecycle leads to the functionally based naming of this approach as the Reconfigurable Logistics Shelter Concept. The second approach recommended for continued investigation ${ }^{1}$ utilized International Space Station (ISS) based crew quarters as the basis for the shelter and enhanced its shielding through application of non-parasitic mass items such as contingency water and easily relocated logistics. This waterwall portion of this concept can either be automatically filled from the vehicle water supply using a Positive Expulsion Device (PED) or manually filled from Iodinated Contingency Water Canisters (ICWCs). 


\section{A. Reconfigurable Logistics Shelter Concept}

The approach for the Reconfigurable Logistics shelter concept is to utilize easily accessible logistics from another part of the habitat to create a mass protected central region of increased safety from radiation exposure. Reference 1 indicated that a group shelter is the optimal configuration for volumetric efficiency for temporary protection from an SPE. Figure 1 shows how, in an ISS style rack based arrangement, four crew might fit into such a volume. The walls are created by first hanging unfolded Cargo Transfer Bags (CTBs) from structural attachment points on the rack faces. Then, logistics items such as food, contingency water, wipes, and trash can be attached to these bags such that they provide a uniform layer of protection. The major advantage of the resulting shelter is that it achieves low parasitic mass by depending fully available items which must be on board the habitat for nominal mission operations. As the mission progresses, the proportions of items which make up the shelter change as items such as food and wipes are converted to waste and trash. In order to ensure that adequate protection is available at any time during the mission, unique storage devices and trash processing techniques are used to ensure waste and trash are still viable for shelter construction. Common Protection Containers (CPCs) such as those shown in Figure 2, are designed to hold wet trash and human waste products in a sealed container designed to stack with minimal gapping. Heat Melt Compactor bricks $s^{2,3}$ as well as dry and wet trash containment is considered in maintaining a supply of available logistics for protection during the full course of a long exploration mission. Other items used to create the shelter walls such as Food Storage Pouches, modified Cargo Transfer Bags, and Iodinated Contingency Water Containers are discussed in the Crew Quarters Shelter section of this report. One potential weakness of the reconfigurable logistics concept is the potentially large amount of crew time required to construct the shelter. However, many solutions exist to facilitate shelter construction such as prearranging logistics into sheets of multiple containers which can be moved and hung with greatly reduced effort than single bags. More specific design feature will be discussed with the shelter evaluations in Section V.

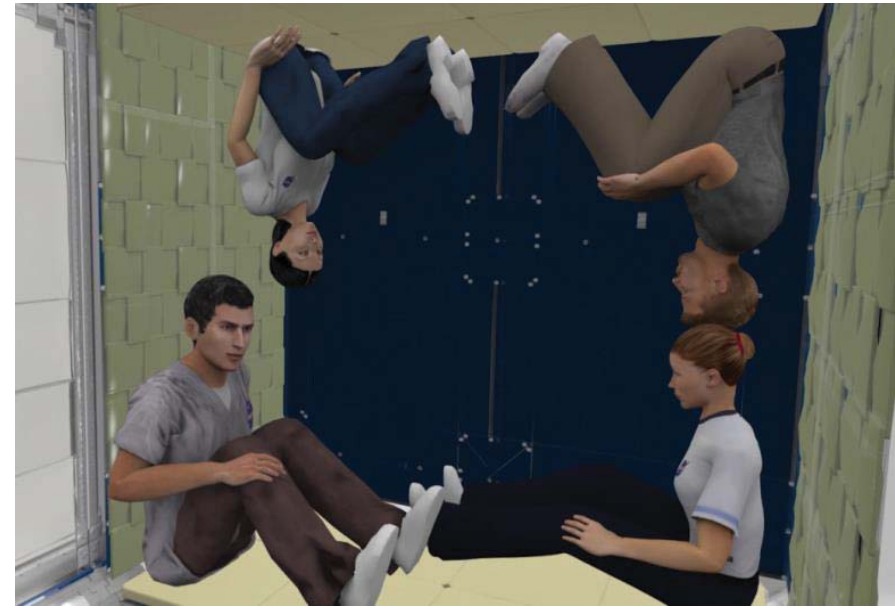

Figure 1: Reconfigurable logistics shelter concept deployed in central aisle

\section{B. Crew Quarters Shelter with Integrated Water and Pantry Walls}

An alternative option to a centrally-located reconfigurable logistics shelter is a crew quarters derived concept. There are numerous advantages to a crew quarters-based radiation shelter. A major advantage is that the space within the crew quarters has been designed and proven for human occupation durations approaching the length of an SPE. The crew quarters has been designed for sufficient ventilation, volume, and lighting and includes other support items designed to make the time spent in the shelter less taxing. Crew members are accustomed to working for prolonged periods within their crew quarters and have the ability to perform some of their daily tasks from this location. Crew activity functions such as clerical work, reading, and sleeping are already provided for in this living space. The main issue is to ensure that the enhanced crew quarters provide an adequate level of protection from a SPE.

The conceptual design for the conversion of a crew quarters into a radiation storm shelter uses a multi-system approach. The multi-system approach is based on the idea that different concepts, materials, and components will provide protection against radiation to different areas of the crew quarters. One protection system is an integrated food and logistics storage system, or pantry, designed to fit into the side walls of a crew quarters. Items can be stored in color coded CPCs and Food Storage Pouches (FSPs) specially designed to fit within the sidewalls, as 
illustrated in Figure 2. Items such as food, logistics, potable water, and wet trash can be stored in the crew quarters walls to provide some level of radiation protection.

Another radiation protection system featured in the crew quarters shelter is the water wall. The water wall is designed to provide protection along the exterior wall of the crew quarter adjacent to the exterior surface of the spacecraft. The water wall should be at least 4 inches thick to provide effective SPE radiation protection in the deep space environment ${ }^{1}$. Conceptually, the water wall would be fabricated using multiple inflatable bladders that have some type of overlapping features as necessary to ensure full coverage of on the surface. These bladders can either be simple bladders which are operationally constrained to be filled and drained with minimal entrainment of air, or Positive Expulsive Device (PED) bladders, which use air outside the water bladder to squeeze the water out of the bladder. The expected advantage of the PED is in easier operations and having less chance of air mixing with the stowed water. Both the bladder and the PED could be plumbed to the habitat water distribution system, or utilize temporary fluid connection to an ISS typical Potable Water Dispenser (PWD), or actually be filled/drained manually with ISS style Iodinated Contingency Water Containers (ICWC's). Using multiple sets of these bladders is necessary since water on board of a space craft is often maintained in different states as the water is processed and purified such as wastewater, cooling water, and drinking water supply. The bladders could be used as holding tanks for the liquid when not circulated or during the processing phase. Plumbing from and to the bladders is needed to circulate the fluids during normal operation cycles. However, the bladders, and the plumbing system would not be considered as a significant increase in parasitic mass since they would be required in any case in the absence of the water wall. Another advantage is that walls could be permanently filled to provide some degree of continuous protection for crew against galactic cosmic rays.

The main argument against the water wall is the amount of water or other fluids required to achieve the 4 inch thickness and the fact that this fluid will be unavailable to other systems during a shelter emergency. However, the feasibility of the water wall remains arguable until the full requirements for a spacecraft are well defined, and the total mass of water and other fluids available is known. Long duration missions are likely to carry a sizable amount of contingency water which would negate this concern.

Figure 3a shows two ISS-type crew quarters located side by side which have been redesigned to include a water wall structure. This concept utilizes a crew quarters similar to those in the International Space Station (ISS), but with integrated hollow structural walls that would be filled with water to provide radiation protection. During an SPE, four crew members can be sheltered as illustrated in Figure 3b. To preserve the inner mold line of the original design, wall thickness increases are applied outward. These walls and/or individual wall panels can then be filled and/or drained on an as needed basis for radiation protection.

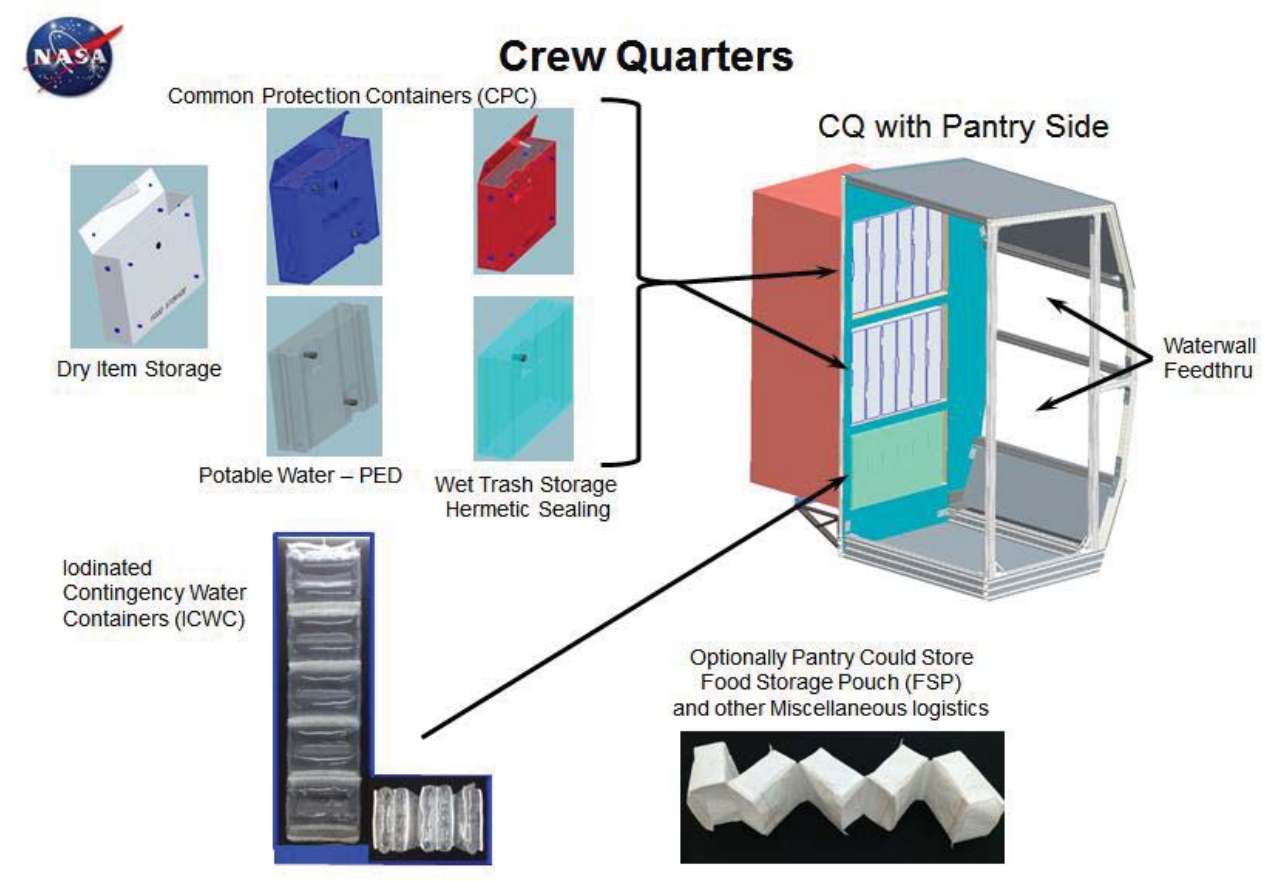

Figure 2: Crew quarters test article utilizing logistics storage and a water wall for radiation protection. 


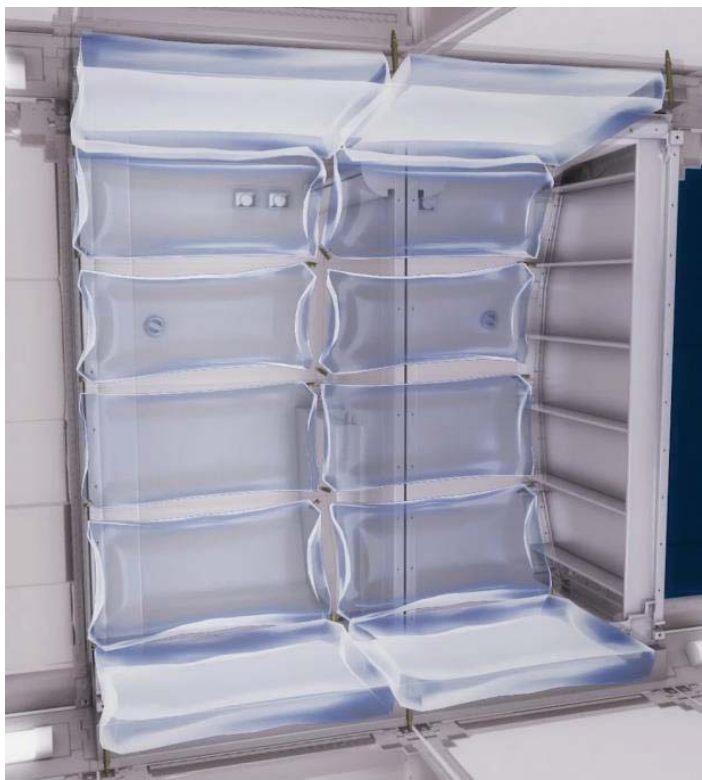

(a) Water wall integration

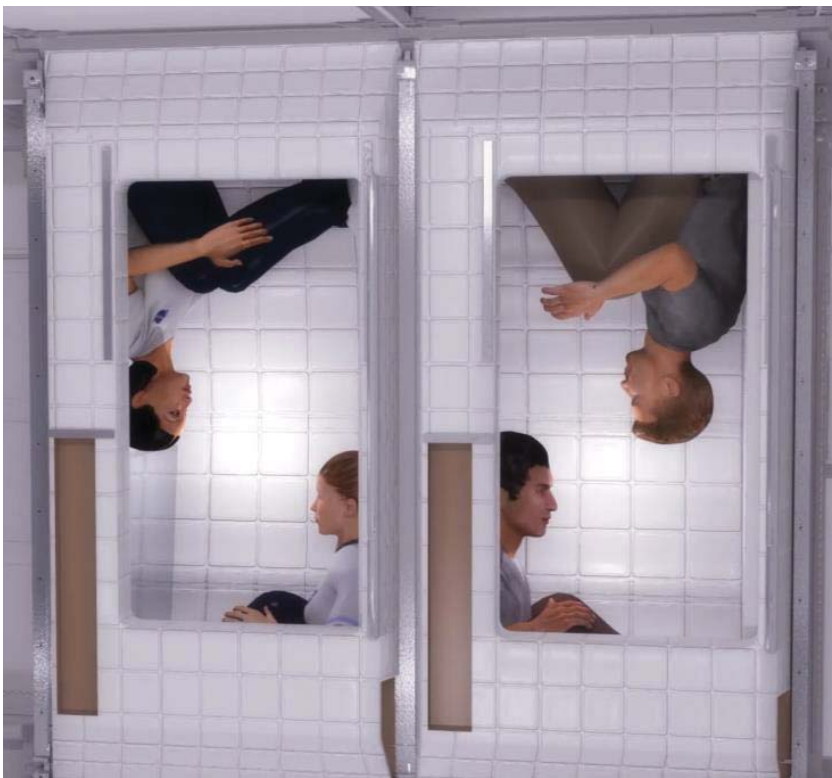

(b) Crew member positions during an SPE

Figure 3: Water wall concept integrated into crew quarters shelter concept

\section{Notional Mission and Habitat Concept}

In order to assess the efficacy of the two shelter design concepts, a purely notional mission and habitat concept (not currently being planned by NASA) must be defined including notional mass breakdowns and an interior layout design. For the FY'13 effort, the focus was on designing shelters for the near term mission concept of a cislunar habitat which would enable long duration testing and demonstration of long duration deep space capabilities such as radiation protection and crew psychology countermeasures. This mission could also be used as a proving ground for an integrated SPE shelter concept to verify that adequate protection is achieved with a reasonable amount of crew time and effort. This baseline mission involved supporting four crew for up to 180 days without logistics resupply and included 30 days of contingency logistics and fluids for critical items such as food, oxygen, and water.

The notional cislunar habitat designed for this analysis combined two modules which would be aggregated to provide this 180 day capability. In order to provide the CAD details necessary for a preliminary radiation analysis, adapted ISS modules were used to construct this habitat. A Node 2 - derived Cis Lunar Spacecraft (CLS) would be delivered first with subsystems and accommodations capable of supporting early 30 day missions. Then a Multipurpose Logistics Module - derived Augmentation Module (AM) is delivered with additional logistics, accommodations, and subsystems to necessary to support a 180 day mission together with the other module. This module would include exercise, crew quarters, a galley, and closed-loop life support equipment. The equipment and logistics would be spread across the vehicle to make the habitat suitable for housing four crew prior to the 180 day stays.

In order to perform radiation analysis and perform human evaluations of these concepts, the mass, volume, and arrangement of the habitat structure, systems, and logistics were parametrically modeled using a combination of the documented structural masses of the chosen modules and a parametric vehicle sizing tool, Exploration Architecture Model for IN-space and Earth-to-orbit (EXAMINE), which has been used by the Human Spaceflight Architecture Team (HAT) Habitation team to support the design of future exploration missions. ${ }^{4,5}$ The specific assumptions used to generate the mass summaries shown in Figure 4 and Figure 5 are included in Appendix A. In these figures, the structures masses are highlighted red to indicate that the existing structures masses of the Node 2 and MPLM were used in place of a parametric estimate. Also, the 30 days of logistics in the CLS (Node 2) were ignored for the creation of the layout and CAD model. These masses and the associated volumes of the subsystems were used to generate the interior layout used for the radiation analysis shown in Figure 6. The assumed systems delivered in each module are as follows: 


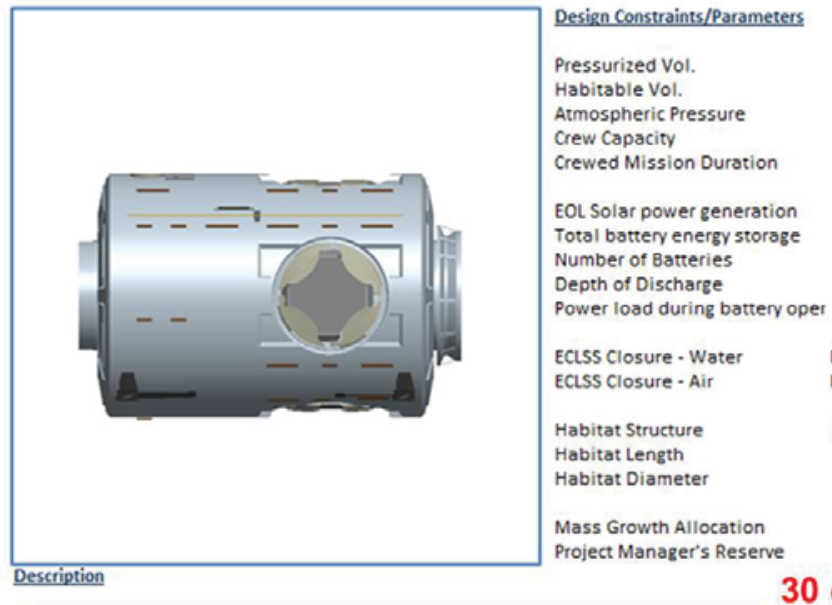

Cis-Lunar Spacecraft (CLS) is sized for a 30 day mission in cis-lunar space.
30 days of

logistics

excluded from

the 180 day configuration

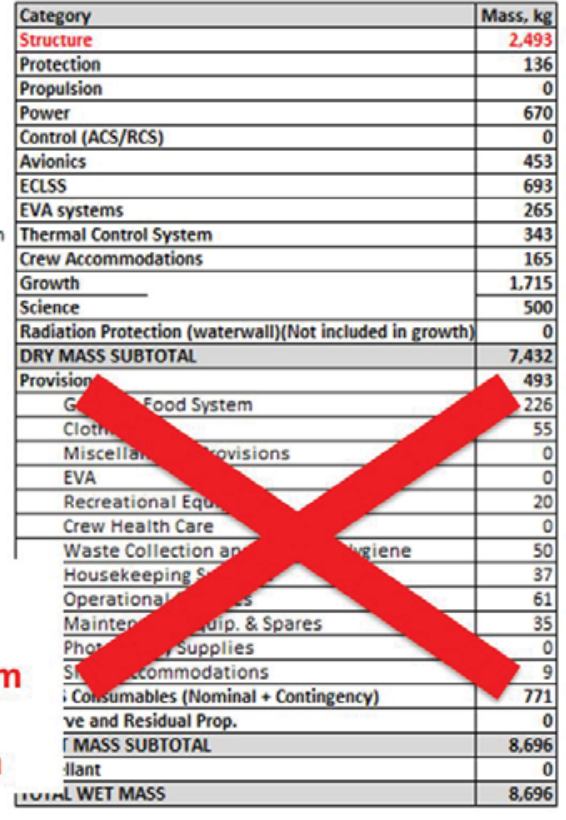

Figure 4: Notional Cislunar Spacecraft (Node 2) mass estimate

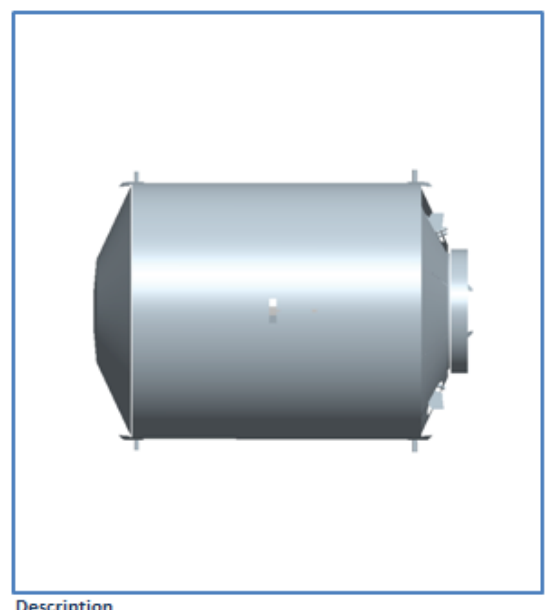

Design Constraints/Parameters

Pressurized Vol.

Habitable Vol.

Atmospheric Pressure

Crew Capacity

Crewed Mission Duration

EOL Solar power generation

Total battery energy storage

Number of Batteries

Depth of Discharge

Power load during battery operi

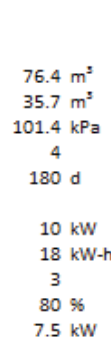

ECLSS Closure - Water

ECLSS Closure - Air

Habitat Structure

Habitat Length

Habitat Diameter

Mass Growth Allocation

Project Manager's Reserve

Partially Closed Partially Closed

I Rigid Cylinder

$4.40 \mathrm{~m}$

4.40

2096

$10 \%$

\begin{tabular}{|l|r|}
\hline Category & Mass, kg \\
\hline Structure & 2,305 \\
\hline Protection & 140 \\
\hline Propulsion & 0 \\
\hline Power & 848 \\
\hline Control (ACS/RCS) & 0 \\
\hline Avionics & 453 \\
\hline ECLSS & 3,020 \\
\hline Air Subsystem & 1,164 \\
\hline Water Subsystem & 911 \\
\hline Food (storage) & 36 \\
\hline Human Accommodations & 0 \\
\hline Other & 908 \\
\hline EVA systems & 0 \\
\hline Thermal Control System & 559 \\
\hline Crew Accommodations & 1,134 \\
\hline Growrth & $\mathbf{2 , 6 8 8}$ \\
\hline Science & 500 \\
\hline Radiation Protection (waterwall)(Not included in grow & 0 \\
\hline DRY MASs SUBTOTAL & 11,646 \\
\hline Provisions & $\mathbf{4 , 2 2 7}$ \\
\hline Galley \& Food System & 1,349 \\
\hline Clothing & 274 \\
\hline Miscellaneous Provisions & 238 \\
\hline EVA & 0 \\
\hline Recreational Equipment & 100 \\
\hline Crew Health Care & 125 \\
\hline Waste Collection and Personal Hygiene & 174 \\
\hline Housekeeping Supplies & 199 \\
\hline Operational Supplies & 166 \\
\hline Maintenance Equip. \& Spares & 1,447 \\
\hline Photography Supplies & 120 \\
\hline Sleep Accommodations & 36 \\
\hline ECLSS Consumables (Nominal + Contingency) & $\mathbf{8 5 7}$ \\
\hline Reserve and Residual Prop. & 0 \\
\hline INERT MASS SUBTOTAL & 16,730 \\
\hline Propellant & 0 \\
\hline TOTAL WET MASS & 16,730 \\
\hline II & \\
\hline
\end{tabular}

Figure 5: Notional Augmentation Module (MPLM) mass estimate 


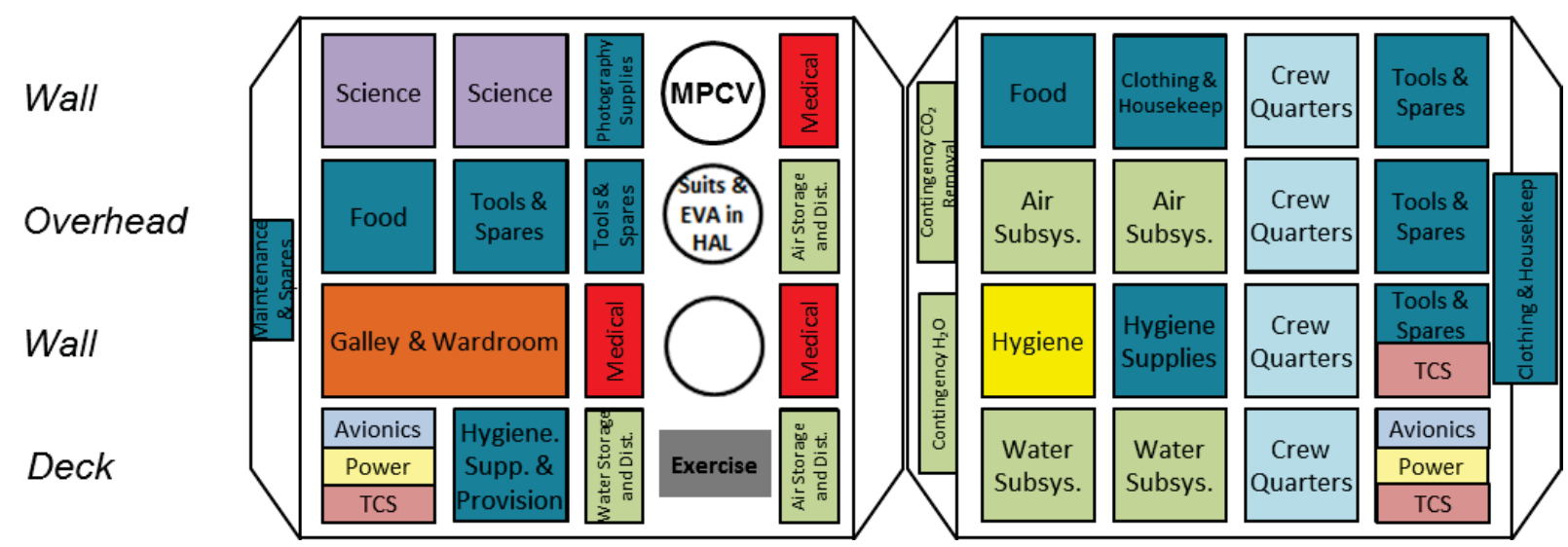

Figure 6: Cislunar spacecraft layout used for as basis for CAD model used for radiation analysis

- Node 2 CLS will nominally have the following remaining after a 30 day mission:

- 1 rack for batteries, power management and distribution, thermal control, and avionics

- 1 box (0.31 m3 for medical supplies)

- Combined with medical suite into for 180 days

- 1 box maintenance equipment $\left(0.53 \mathrm{~m}^{3}\right)$

- 2 midbays for atmosphere storage and distribution equipment

- 1 midbay for water storage

- 1 rack of science equipment

180 day mission additionally requires the following:

- 4 racks for crew quarters

- 1 rack for power conditioning, batteries, thermal control, and avionics

- 3 midbays in Node for medical suite and supplies

- 1 Node hatch location for exercise equipment

- 1 rack for galley equipment, supplies and a small pantry of food

- 2 air subsystem racks (includes nominal and contingency oxygen storage)

- 2 water processing racks

- 1 hygiene compartment rack (includes commode, urine collection system)

- 1 rack of science equipment

- 2 racks of food storage

- 2 racks of hygiene supplies, operational and miscellaneous provisions

- 1 clothing and housekeeping supplies rack and $1 \mathrm{~m}^{3}$ bag on rear of MPLM

- 1 photography midbay

- 4 tools and spares racks

These systems and logistics were reorganized into the layout in Figure 6 which was designed to consider desired functional adjacencies, reduced utility run mass, human factors, and radiation protection. In particular, a centralized location surrounded by somewhat dense subsystems was provided for the reconfigurable logistics shelter concept. Additionally, some logistics were placed far from the designated shelter areas to allow for relocation to increase local protection in shelter concepts. This interior layout was used as the basis for the radiation analysis CAD model described in Section IV.

\section{Radiation Analysis}

A radiation analysis was performed to determine the amount of shielding necessary to protect crew from an SPE in the vehicle described in the previous section. This section describes the process used, which is very similar to the process used in the previous year's analysis ${ }^{1,6}$, but now utilizes new probabilistic analysis to model the SPE spectra. 


\section{A. Radiation Analysis Process}

\section{A Probabilistic Approach}

A new probabilistic analysis process, which takes into account the varying nature of SPE spectra as well as uncertainty related to SPE protection requirements for future missions, was utilized to determine the quantity of protection materials needed for each of the concepts. For each version of each shield concept, the reduction in astronaut exposure was calculated for varying shield thicknesses. These calculations were performed for a database of SPE environments and probability density functions (PDFs) were developed for each shield thickness. Using this approach, the reduction in exposure could be examined at various confidence levels. A 1-sigma (68\% confidence interval) was used for this effort and the shield mass which provided the needed level of protection at this confidence level was identified for each concept. Using this process, the protection provided by multiple versions of each of the two concepts was evaluated and the configurations which provided the largest reduction in astronaut exposure per unit mass were identified.

These calculations were performed for a database of SPEs, because historic SPEs have varied in magnitude and spectral shape. For this reason, choosing one SPE spectrum to use as a design basis might not ensure that shielding concepts do provide adequate protection. The use of multiple SPE spectra to perform probabilistic risk assessments for SPE exposure was originally put forward by Kim, et al. ${ }^{7}$ The approach detailed here focuses on reduction in exposure, and this effort utilized a database of SPE spectra developed by Xapsos for inclusion in his probabilistic event spectrum modeling effort ${ }^{8}$. This database includes events which occurred between November 3, 1973 and October 22, 2001 as measured by the Interplanetary Monitoring Platform (IMP) and Geostationary Satellite System (GOES) satellites. For this effort, the database of SPE spectra was reduced to only those SPEs which would provide an astronaut inside an aluminum sphere $3 \mathrm{~g} / \mathrm{cm}^{2}$ thick with an effective dose of $1 \mathrm{mSv}$ or more.

Another challenge for designing SPE protection concepts is the large uncertainty related to SPE protection requirements for future human exploration missions. NASA's current Permissible Exposure Limits (PELs) can be found in NASA Standard 3001Volume $1^{9}$. This document contains short term limits and requirements related to career exposure. However, while the short duration limits could be very important, especially if a large SPE were to occur while astronauts were performing extravehicular activities, the requirements to keep astronaut risk of exposure induced death (REID) under 3\% at a 95\% confidence and to keep astronaut exposure "as low as reasonably achievable" (ALARA) drive the design of SPE shelters. If these requirements are met for astronauts inside the shelter concepts, the 30 day limits will also be met.

Ensuring that the REID requirement is met is more challenging, because this requirement applies to the astronauts' total career radiation exposure from SPEs, from GCR, and from particles trapped in the Earth's magnetic field; and GCR exposure for long duration missions will be substantial. Predictions for the number of safe days in space vary, depending on the assumptions made and the risk models used, but most models show that astronaut GCR exposure during a mission to Mars or even to an asteroid would exceed the requirement to keep REID under $3 \%$ at a $95 \%$ confidence $^{10}$ and astronaut exposure from SPEs would raise the REID even higher. In this situation, it is difficult to define requirements for SPE shelters that will meet the needs of all future exploration missions. For this effort, the primary key performance parameter was defined in terms of reduction of astronaut exposure, with a "must meet" threshold of $50 \%$ reduction and a goal of $70 \%$. Focusing on reduction in astronaut exposure enables comparisons of multiple options, protection provided versus mass required, ensuring a substantial reduction in astronaut risk and demonstrating that chosen concepts meet the ALARA requirement. While this process cannot guarantee that shield designs will meet the requirements of all future missions or be compatible with future vehicles, it does provide evidence that the identified concepts could be used, possibly with some adaptation, for those missions.

\section{Transport and Reduction in Effective Dose Calculation}

When particles making up the space radiation environment impinge on spacecraft materials, they lose energy and secondary particles are produced when nuclear collisions occur. All of the materials surrounding the astronauts have an impact on astronaut radiation exposure. For this reason, the first and often the most time consuming step in any exposure analysis process is developing a model of the spacecraft which accurately represents the masses of all vehicle components and onboard equipment, food, water, and cargo. The cislunar spacecraft described in the previous section is shown in Figure 7 with all of the attached Quest airlock and two propulsion modules. A simple model of the Multi-Purpose Crew Module (MPCV) was also developed and attached to the node. Equipment, supplies, and cargo needed for a 180 day mission with a crew of four were also incorporated into the CAD model at appropriate locations. 


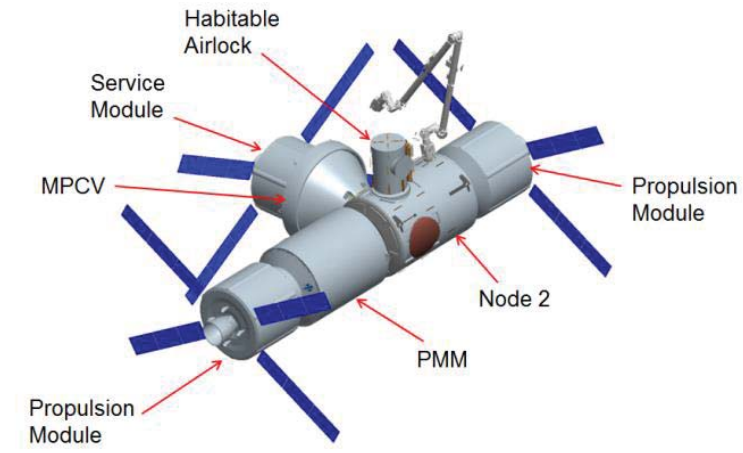

Figure 7: Cis-lunar spacecraft used for radiation analysis

Initial, baseline analyses were performed for the spacecraft in this form. The CAD model was then altered first to model the crew quarters shelter concept in the spacecraft and later to model the central reconfigurable logistics shelter concept in the spacecraft. For both types of shelter, food, water, and cargo necessary to create the shelter would be moved from their original locations. For analysis purposes, the shelter materials were modeled as walls of water and the areal densities, in units of $\mathrm{g} / \mathrm{cm}^{2}$, needed to achieve the desired reduction in astronaut exposure were calculated. Areal density is length scaled by density. The total mass required for each concept was then calculated based on the areal densities. The majority of the shielding materials: water, packaged food, and hygiene and housekeeping supplies, have significant hydrogen content, so the use of water should be an acceptable approximation. However, the actual thicknesses, in units of length such as centimeters or inches, of the shields will vary depending on the density of the material and the gaps produced when the shelter is formed.

For this effort, astronaut radiation exposure was evaluated in terms of effective dose. Effective dose is a measure of whole body exposure. It was determined by calculating the dose equivalent at 1214 points in a female body and taking a weighted average of those values using tissue weighting factors to account for the varying sensitivity of the various organs and tissues. Dose equivalent is calculated with quality factors which take into account the cancer risk posed by different types of radiation. Solid cancer and leukemia quality factors and tissue weighting factors recommended by Cucinotta, et al. ${ }^{11}$ were used. Assessments were performed for a female, because REID is higher for females ${ }^{10,11}$ and the lower body mass provides less protection for sensitive organs, so a shelter designed for female astronauts should provide adequate protections for their male counterparts.

The transport of the external environments through the shielding materials and human tissue was calculated using a version (TARIS Fortran code revision 3.4) of the HZETRN space radiation transport code ${ }^{12,13}$ developed for and currently used by the On-Line Tool for the Assessment of Radiation In Space (OLTARIS) ${ }^{14}$. First, for each SPE environment, a dose equivalent versus shield thickness database, which included combinations of varying thicknesses of aluminum, polyethylene, and human tissue, was created. Then, for each effective dose calculation, the CAD model of the spacecraft (with or without one of the shielding concepts) was "ray traced" at five locations corresponding to the astronaut's head, chest, pelvis, thighs, and lower legs. A ray tracing code which utilizes the Sigmaxim SmartAssembly ${ }^{\mathrm{TM}}{ }^{15}$ tool set, an analysis add-on for Pro/Engineer CAD software, was used to calculate the thickness of each type of material between the external environment and the ray trace point along 1002 rays which evenly cover the full $4 \pi$ steradians. The spacecraft ray traces were then combined with pre-existing ray traces of the Female Adult voXel (FAX) phantom ${ }^{16,17,18}$. The dose equivalent at each of the 1214 body points was then calculated by first interpolating over the dose equivalent versus thickness database for each of the 1002 rays and then averaging those results.

\section{B. Radiation Analysis Results}

\section{Astronaut Exposure without Shielding Concepts}

Before the probabilistic analysis of the shielding concepts was performed, astronaut exposure was evaluated at several locations in the spacecraft for several fits to historic SPEs, which have been used in other studies ${ }^{6}$, and for a spectrum representing an upper $95^{\text {th }}$ percentile for all SPE protons produced during a one year mission, which was created using Xapsos's Emission of Solar Protons (EMS) tool ${ }^{8}$. Of these spectra, only the October 1989 event spectrum was taken from the SPE database used for the probabilistic analyses and it is the largest event in that database. The results of this analysis are presented in Table 1 and the astronaut locations: treadmill, galley, hygiene unit, and four crew quarters (CQ), are shown in Figure 8. The need for a probabilistic approach using multiple SPE 
spectra is demonstrated by the large variation in results depending on the SPE spectrum used. It should also be noted that some of these effective dose values are quite large, demonstrating a clear need for protection concepts. There is also a large variation in results depending on the astronaut location; with astronauts receiving lower effective doses at the internal locations and higher effective doses in the crew quarters. For the reduction in exposure analyses performed to evaluate the SPE protection concepts, the astronaut's effective dose in the shielding concepts was compared to the effective dose at the treadmill location.

Table 1: Astronaut effective dose for various SPE spectra

\begin{tabular}{|l|c|c|c|c|c|c|}
\hline & \multicolumn{7}{|c|}{ Effective Dose (mSv) } \\
\hline & $\begin{array}{c}\text { Aug. '72 } \\
\text { (King) }\end{array}$ & $\begin{array}{c}\text { Aug. '72 } \\
\text { (Band fit) }\end{array}$ & $\begin{array}{c}\text { Sept. '89 } \\
\text { (OLTARIS) }\end{array}$ & $\begin{array}{c}\text { Sept. '89 } \\
\text { (Band fit) }\end{array}$ & $\begin{array}{c}\text { Oct. '89 } \\
\text { (Xapsos - GOES) }\end{array}$ & $\begin{array}{c}\text { One Year 95 Percentile } \\
\text { (Xapsos - ESP) }\end{array}$ \\
\hline Treadmill & 161 & 108 & 71 & 63 & 221 & 275 \\
\hline Galley & 81 & 65 & 47 & 38 & 149 & 168 \\
\hline Hygiene Unit & 133 & 98 & 74 & 63 & 229 & 282 \\
\hline Top CQ & 480 & 271 & 132 & 136 & 409 & 591 \\
\hline Bottom CQ & 505 & 283 & 133 & 139 & 412 & 602 \\
\hline Left CQ & 398 & 227 & 121 & 121 & 373 & 526 \\
\hline Right CQ & 526 & 297 & 138 & 144 & 427 & 626 \\
\hline
\end{tabular}

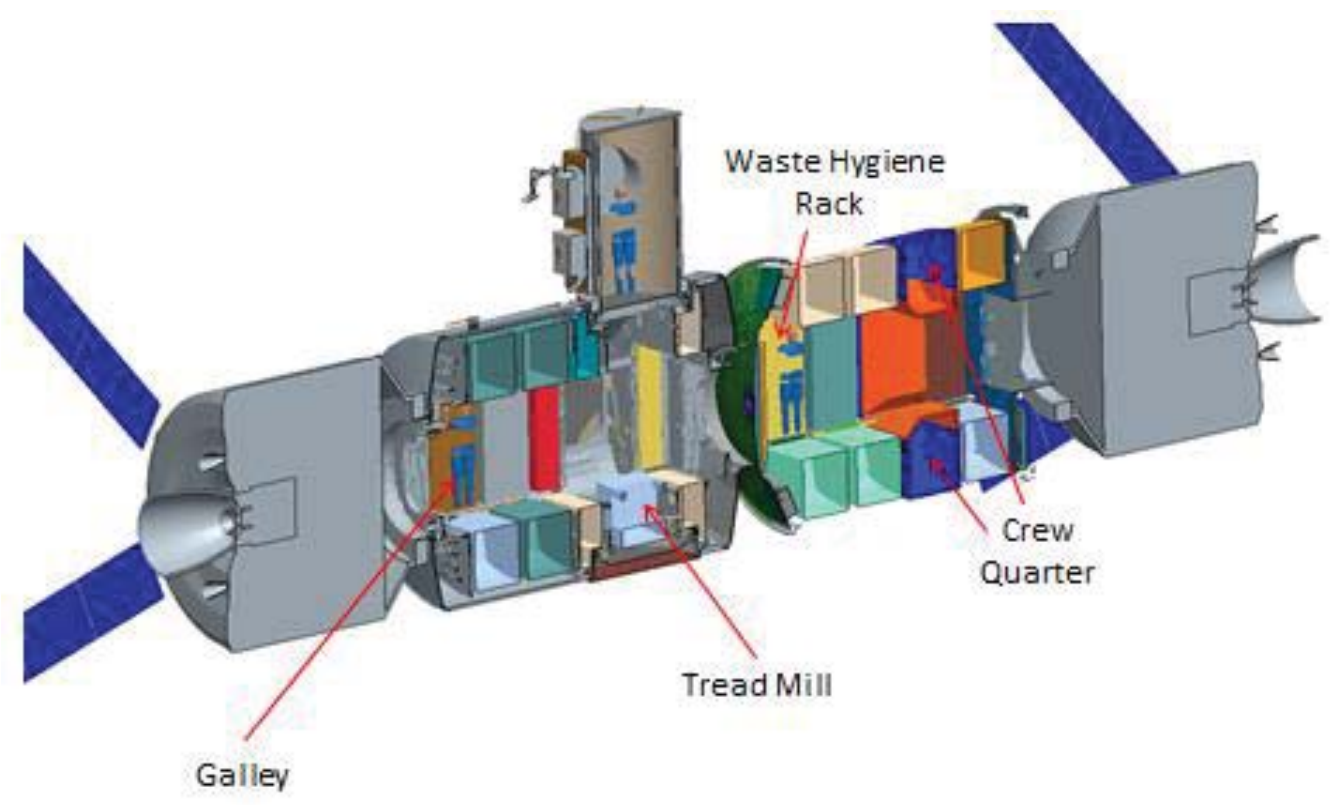

Figure 8: Astronaut locations in spacecraft

\section{Crew Quarters Concept}

The initial assumption for the crew quarters concept was that protection would be provided in all four crew quarters and that the back, top, bottom, and sides, but not the bump out (door), of each of the crew quarters would be augmented equally (Case 1). However, three alternate configurations were also examined. In Case 2, the back, top, and bottom of each of the crew quarters were augmented equally. In Case 3, only the backs were augmented. Finally, in Case 4, only the backs and the sides were augmented. It was also assumed that 5,189 lbm (2,354 kg) of food, water, and supplies pulled from racks in the node and at the end of the MPLM module farthest from the crew quarters would be available for use in the shelters.

Figure 9 shows the results of this analysis for the crew quarters located on the right side of the spacecraft. The solid curves represent the median estimates for reduction in effective dose and the error bars show the 1-sigma confidence intervals. This plot clearly shows that the only viable configurations for a $50 \%$ reduction in exposure are Cases 1 and 4, and that Case 1 is preferable in terms of mass. However, this plot also shows that the augmentation mass to ensure a $50 \%$ reduction at a $68 \%$ confidence would be $2,883 \mathrm{lbm}(1,308 \mathrm{~kg})$ for this single crew quarters. This mass corresponds to water walls 8.1 inches $\left(20.7 \mathrm{~g} / \mathrm{cm}^{2}\right)$ thick. Shielding required for the other crew quarters 
varied slightly, ranging from 2,781 lbm to 2,957 lbm (1,261 kg to 1,341 kg), depending on the content of the neighboring racks and the shielding provided by other modules, specifically the MPCV and the airlock. With a total mass requirement of 11,459 lbm (5,198 kg), this was not deemed a viable option.

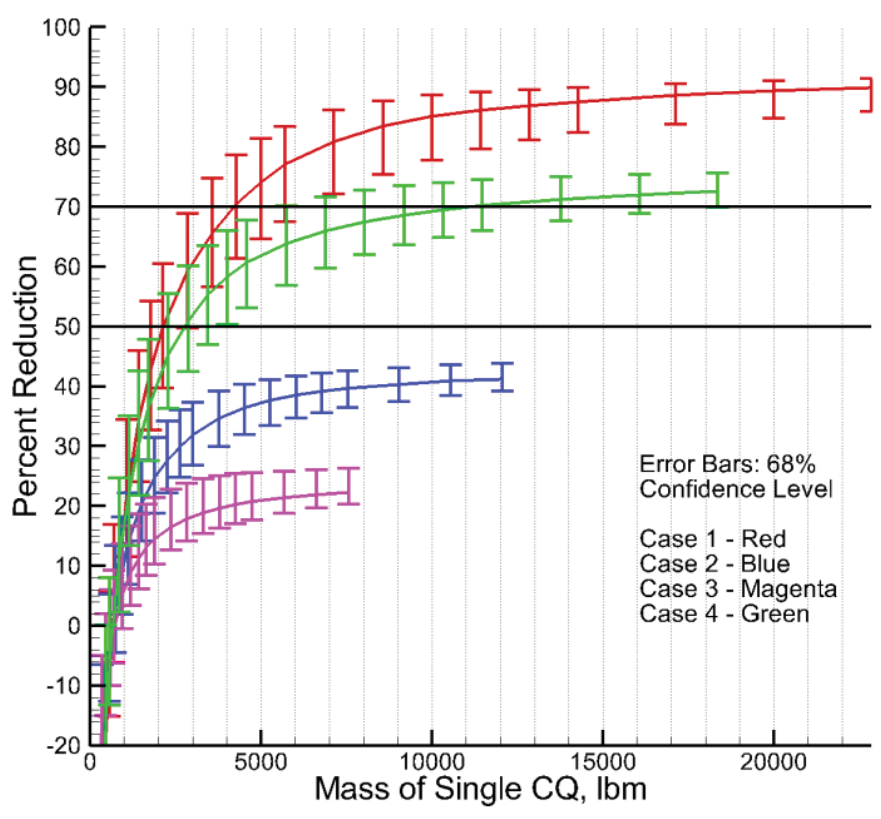

Figure 9: Percent reduction in effective dose plotted as a function of shield mass for four versions of a crew quarters based storm shelter. Case 1: equal augmentation to back, top, bottom, and sides. Case 2: equal augmentation to back, top, and bottom. Case 3: augmentation to back only. Case 4: equal augmentation to back and sides.

An adaptation to this concept for which astronauts would "double up," two to a crew quarter, was then examined. This version was expected to result in a lower shield mass, because only two of the crew quarters would be augmented and the astronauts would provide some shielding to each other. Two possibilities were considered, augmenting adjacent crew quarters and augmenting opposite quarters. Analysis of these two options showed that the augmented crew quarters needed to be on opposite sides of the vehicle, so that they provided shielding for each other. Analysis also showed that Case 1, augmenting the backs, tops, bottoms, and sides, was once again the best option. For this configuration, 4.3 inches $\left(10.8 \mathrm{~g} / \mathrm{cm}^{2}\right)$ of water shielding was required for a $50 \%$ reduction in astronaut effective dose. This corresponded to a total shielding mass for both crew quarters of 2,943 lbm (1,335 kg), approximately one quarter the mass required to shield the four separate crew quarters. Based on this result, this version of the crew quarters shelter was deemed viable. However, 10.1 inches $\left(25.6 \mathrm{~g} / \mathrm{cm}^{2}\right)$ or a total of $10,440 \mathrm{lbm}$ $(4,736 \mathrm{~kg})$ of shielding materials were needed for a $70 \%$ reduction in astronaut exposure at a $68 \%$ confidence, which would result in a large reliance on parasitic mass. This was not deemed a practical option.

\section{Central Reconfigurable Logistics Concept}

The initial version of the reconfigurable logistics concept utilized a section of the corridor two racks long as shown in Figure 10. The shelter consisted of two end panels and two panels on each side, each one covering one rack face. This concept provided a habitable volume of approximately $8 \mathrm{~m}^{3}$, similar to that of the four crew quarters combined. This concept took advantage of the shielding provided by the adjoining full racks, and was, therefore, expected to require a smaller quantity of shielding materials than the comparably sized four crew quarter concept. The disadvantage of setting up a shelter next to full racks, though, is that there are fewer materials left available to be moved to create the shelter, in this case, 2,870 lbm (1,302 kg). 


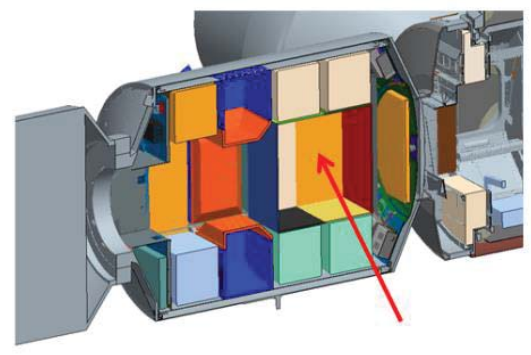

Figure 10: Initial large version of the reconfigurable logistics shelter

A variety of cases were evaluated which involved varying the thickness of some of the panels while holding others fixed. Of the cases that were examined, augmenting all of the panels equally was shown to be optimal. However, the analysis also showed that $6,282 \mathrm{lbm}(2,849 \mathrm{~kg})$ of shielding materials would be required to ensure that the effective dose for all four of the astronauts was reduced by $50 \%$ with a $68 \%$ confidence. While this is much smaller than the mass required for the four crew quarter system, parasitic mass would still be required. Therefore, like the four crew quarter concept, this version of the reconfigurable logistics concepts was not deemed viable.

A smaller volume adaptation of this concept was then examined. In this version, the shelter was located at the end of the MPLM closest to the node and was only one rack wide, as shown in Figure 11. Also, for this version, a food rack, which was originally located to left of this shelter, was swapped with a rack full of tools and equipment, which was originally located at the opposite and of the MPLM. Moving the racks in this way resulted in a slight reduction in the amount of protection provided by the rack to the sheltered astronaut, but it also resulted in a needed $1,181 \mathrm{lbm}(536 \mathrm{~kg}$ ) increase in the amount of food available for use in the shelter. Analysis of this configuration showed that 3,578 $\mathrm{lbm}(1,623 \mathrm{~kg})$ of shielding materials, corresponding to 3.7 inches $\left(9.3 \mathrm{~g} / \mathrm{cm}^{2}\right)$ of water, would be needed to ensure a $50 \%$ reduction in exposure for all four astronauts at a $68 \%$ confidence. This version of the reconfigurable logistics shelter was, therefore, deemed viable. The shielding mass required for a $70 \%$ reduction at a $68 \%$ confidence, however, was found to be $9,380 \mathrm{lbm}(4,255 \mathrm{~kg})$, which was not deemed practical.
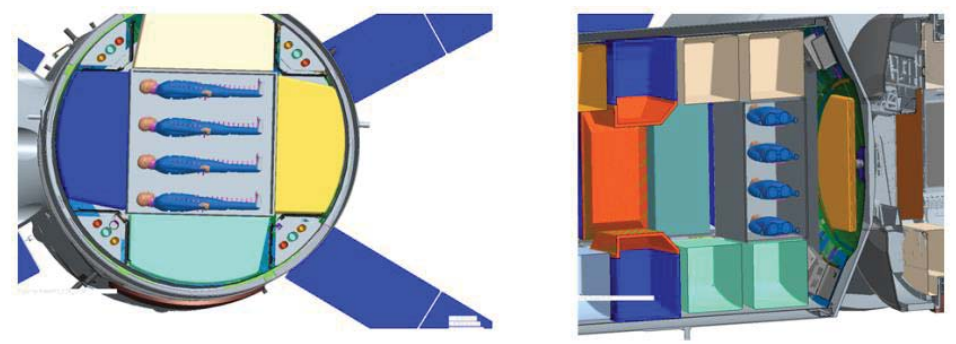

Figure 11: Smaller volume reconfigurable logistics shelter, as seen from the end of the MPLM (left) and as seen from the right side of the spacecraft (right)

\section{Shelter Deployment Testing}

In addition to performing radiation analysis on the two shelter concepts, usability and human performance testing was conducted for each concept. These shelters were assessed to ascertain if the time to construct was appropriate for the typical warning period for solar particle events (SPE), to assess workload levels associated with the construction of these, and to identify usability issues with these particular designs.

\section{A. Crew Quarters-Based Waterwall and Pantry}

The crew quarters (CQ) shelter assumed that side walls were outfitted with shelving, or a pantry wall, that could store logistics as shown in Figure 12. A variety of logistics were used to provide this protection: mock HMC bricks, and thermostabilized and freeze-dried food packages of various forms. Participants were asked to perform two operational scenarios to evaluate the CQ shelter concept. In the first, which assumed a SPE occurred early in the mission, participants stocked the shelves with food packages packed into food storage containers (since early in mission HMC replacement bricks are not available) and removed one of each food type in preparation for a meal. The second scenario was the Non-SPE operational scenario, which was assumed to occur near the end of a mission when the galley food has been consumed. In addition to stocking the shelves, participants assessed pantry wall food removal and brick replacement. Four evaluators walked through each of the scenarios. Each evaluator received 
verbal instructions from a facilitator prior to beginning each task. The experimenter noted the time on task, food items removed from the containment bags, evaluator comments, and general observations on the evaluation form. Once the tasks were completed, the evaluator completed a list questions on the evaluation form regarding packing, access to items, ability to replace food items with bricks, time spent on task. The evaluators also provided ratings on a series of questionnaire items to assess forms of workload (mental, physical, temporal demand, performance, effort, and frustration) using the NASA TLX ${ }^{19}$. Evaluators were also asked to comment on what made the tasks easy/difficult, how the designs could be improved, and to provide any other comments they thought were pertinent.

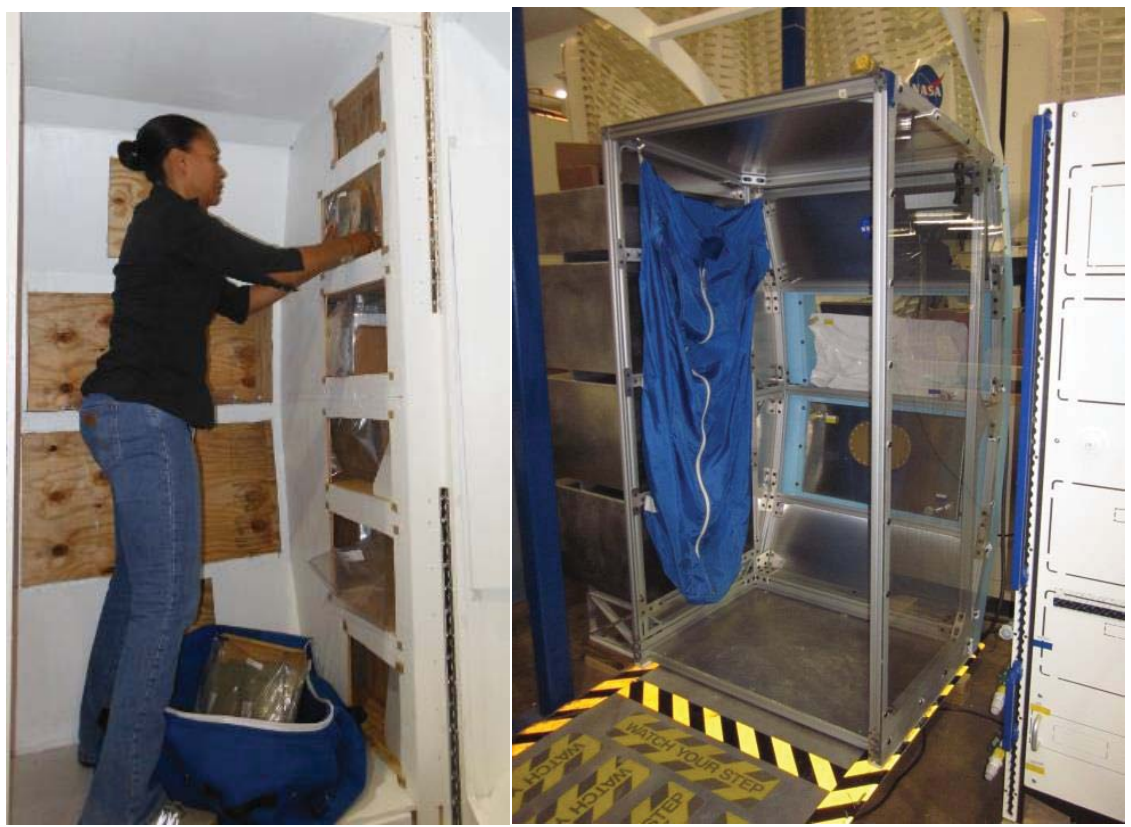

Figure 12: Preliminary and secondary demonstration articles for crew quarters with pantry

Times on task were acceptable, average times for the particular task elements. The average time for loading the food containment bags was slightly less than two minutes for each of the shelves. Removing food during the SPE scenario was completed in, on average, less than a minute. Removing food and replacing this with the HMC bricks (in the non-SPE task) could also be completed in less than two minutes. Workload ratings were very low (less than the middle rating) for scales assessing mental, physical and performance demand. Only one evaluator rated temporal and frustration as higher than the midpoint on the scale, but two participants rated effort higher than the midpoint. Other observations from this study include:

- Loading stiff HMC bricks into the pantry wall was too difficult. Bricks may need to be resized to better match food package dimensions.

- Wall openings may need to be resized, to fit food and containment bags.

- Need a tray, Velcro, or some other means of securing removed food packages.

- More compartments in containment bags so food doesn't slide around.

- One evaluator was reluctant to remove food and compromise shielding during the simulated SPE event.

- Wider 8 in. configuration with freeze dried food preferred by one evaluator. Easier to keep on shelf while searching for a meal.

Lessons learned from this first evaluation of the CQ pantry wall concept focused on:

- Redesign of food storage bags for better containment and organization of food pouches, including pouch overlap in design.

- Using thermostabilized food for better packing efficiency and higher density.

- Potentially resizing HMC bricks to better match volume of three overlapped thermostabilized food pouches - a typical meal, and redesign shelf size for this volume. 
- Consider designs that allow storage bags to overlap within the pantry wall to minimize gaps. (i.e.: consider a wall twice the width of a containment bag, so that a second layer can be placed to overlap gaps.)

\section{B. Reconfigurable Logistics}

The reconfigurable logistics shelter was mocked up as a three-rack-wide section of an ISS-type module as shown in Figure 13. Single CTBs and redesigned FSPs were used to construct this shelter. The actual shelter would be created by deconstructing the CTBs into blankets, hanging these from rails on the top of racks, and securing the redesigned storage bags to these blankets. Ten FSPs were designed to fit into a single CTB. These were designed such that five bags accordion-folded into a block the width, and half the height of a CTB. Each set of five FSPs were held together in this configuration with Velcro, and this Velcro also was used to secure these logistics to CTBs for the evaluation. The evaluation required single and two-person crews to provide protection to only one side wall (three racks wide) and the wall between racks (the spanning wall that is the distance between opposing racks). Participants were asked to both install the shelter and also remove it. To install this shelter, participants used an illustrated, high, task-level (i.e., 'secure logistics' rather than activity-level 'how to secure this particular logistic package') instruction set which guided them to open CTBs, unfold them into blankets, secure these to the racks or spanning wall bar, and affix the FSPs for protection. For this installation task, participants were told that they would nominally have 30 minutes of warning prior to the SPE event for which they required protection. Participants were also asked to deconstruct the shelter and return logistics to reconstructed CTBs. Eight persons, with stature 61" to 72 " and no reported manual dexterity or physical limitations relevant to these tasks, participated in this study. Two participants worked together first on either the spanning wall or the rack wall, then on the other of these; following this, each of the participants in the crew constructed one of these two walls alone. Order of the presentation of spanning and rack wall were counterbalanced over crews.

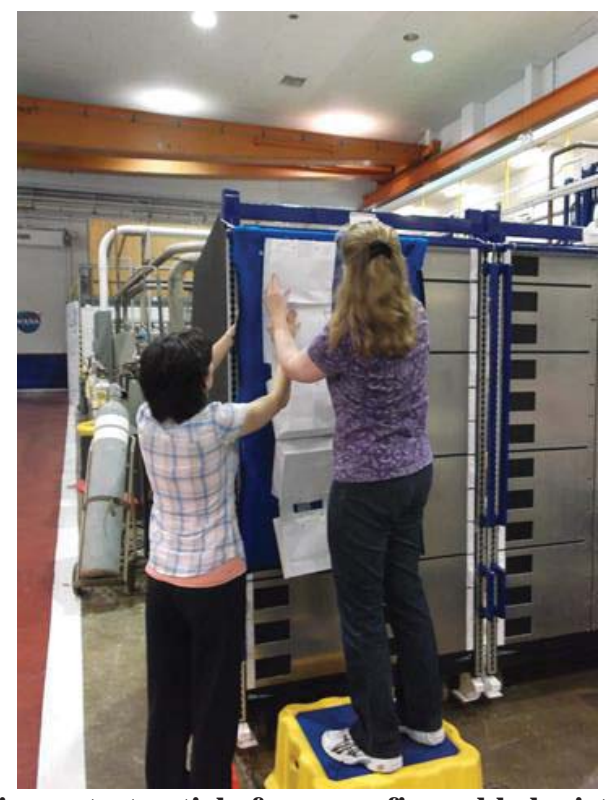

Figure 13: Preliminary test article for reconfigurable logistics shelter concept

Median scores for all conditions (spanning wall and rack wall; single and two-person crews) were significantly less than the midpoint of all NASA TLX workload scales. In all conditions, the Effort and Temporal Demand scales seemed the primary drivers of workload. All but one participant rated the "Dexterity required to accomplish the tasks" as very or perfectly acceptable; and this one provided a midpoint rating. Ratings of "the degree of exertion/discomfort experienced in accomplishing the tasks" were all either very or perfectly acceptable. All participants suggested that it was reasonable to expect to complete the wall task within 10 minutes with crew crewmembers, and two of the four participants who constructed the wall alone indicated that it was also acceptable to complete the shelter in this period. For the spanning wall, participants were less confident in accomplishing the task within 10 minutes. Mean task completion times for the two crew operations were markedly higher for the first runs (950 seconds for the rack wall, and 1190 seconds for the spanning wall) than in the second trials (580 seconds 
for the rack wall, and 620 for the spanning wall). These data indicate a substantial learning effect after only one trial, and this interpretation was reflected in subject commentary; e.g., "used instructions the first time, but then didn't use them." After having experienced two-crew operations, the average task completion times for single crew operations were all between 420 and 590 seconds.

In addition to these data, several usability issues were observed which should inform future designs. The most time-consuming aspect of shelter construction was the deconstruction of the CTBs into blankets. Redesign of these in a manner to minimize deconstruction time would be beneficial. For this installation, blankets were required to be in particular configuration with respect to each other so that zippers on the CTBs could be used to affix these together once in the shelter configuration. Participants found it difficult to determine the appropriate orientation of these. This problem could be obviated by redesign of CTBs and/or shelter construction such that orientation is irrelevant, or mitigated by improved labelling/instruction to make the required orientation more apparent. Participants were required in this shelter design to use the snaps on the CTB blankets to secure these to rack rails and the spanning bar. In this design, snaps were on the back side, and so not visible to participants while trying to secure these; which presented a difficulty to be avoided. While the accordion packaging of the FSPs certainly affords faster affixing of these logistics than would individual application, the degree to which Velcro used in this particular design proved to be challenging; inducing notable nuisance adherences. Future work should reconsider container design for protective logistics such that easy storage in, and extraction from CTBs, and affixing of these to shelter walls is facilitated. Finally, while crews suggested that it was possible to construct shelters alone, two-crew operations were preferred.

\section{Recommendations and Forward Work}

FY'13 efforts in the RadWorks Shelter team resulted in two major conclusions. First, the radiation analysis showed that both of the Crew Quarters based shelter and the Reconfigurable Logistics shelter could achieve enough shielding to reduce the effective doses by $50 \%$ while only adding small amounts of parasitic mass. This analysis also demonstrated that the cases which were analyzed had substantial room for layout optimization to further reduce the dose. It should also be noted these low parasitic mass solutions were achievable using a probabalistic SPE model and a vehicle with a relatively small diameter. Comparing these results to the FY' 12 efforts indicates that a larger diameter habitat may benefit the construction of SPE shelter parasitic mass. The second conclusion was that the shelter usability and human performance evaluations indicated that the shelters could be deployed at a reasonably low workload in a feasible amount of crew time. The evaluations also stressed the importance of having redesigned logistics to facilitate uniform shelters without gaps and to facilitate the deployment operations. These recommendations have been communicated to affiliated AES logistics groups to influence exploration logistics packaging strategies.

Future work for the RadWorks team in its final year focuses on refining the shelter concept design features through continued iteration of testing and building. A more formal set of evaluations with non-project participants will help to understand the appropriate level of training and best construction techniques. In general, this work has demonstrated a need for more generic models to correlate habitat interior layout and the radiation protection strategy to ensure habitats are designed to maximally leverage available resources for GCR and SPE radiation shielding. Finally, a habitat design effort should be undertaken to implement the best practices learned through this project into the latest habitat designs for the Agency.

\section{Acknowledgments}

The authors wish to acknowledge the contributions of all of the members of the AES RadWorks Storm Shelter Team who've worked hard to make this project a success and the AES RadWorks Leadership Team, both past and present, for championing this work and providing valuable guidance.

\section{References}

${ }^{1}$ Simon, M., Cerro, J., Clowdsley, M., "RadWorks Storm Shelter for Solar Particle Event Shielding”, AIAA 2013-5435, AIAA SPACE 2013 Conference and Exposition, San Diego, CA, September 10-12, 2013.

${ }^{2}$ Broyan, J., Ewert, M., "Logistics Reduction and Repurposing Beyond Low Earth Orbit," AIAA-2012-3445 42nd International Conference on Environmental Systems, 17-21 July, San Diego, CA.

${ }^{3}$ Wignarajah, K., Fisher, J., Alba, R., "Development of the Heat Melt Compactor for Management during Long Duration Human Space Flights," AIAA-2012-3545, 42nd International Conference on Environmental Systems, 17-21 July, San Diego, CA. 
${ }^{4}$ Komar, D. R., Hoffman, J., and Olds, A., "Framework for the Parametric System Modeling of Space Exploration. Architectures," AIAA-2008-7845, 2008.

${ }^{5}$ Toups, L., Simon, M., Smitherman, D., Spexarth, G., "Design and Parametric Sizing of Deep Space Habitats Supporting NASA's Human Space Flight Architecture Team", GLEX-2012.05.3.5x12280, Global Space Exploration Conference, Washington, D.C.: IAF, 2012.

${ }^{6}$ Walker, S., et al., "Radiation Exposure Analyses Supporting the Development of Solar Particle Event Shielding Technologies", AIAA2013-3402, AIAA 43 ${ }^{\text {rd }}$ International Conference on Environmental Systems, Vail, CO, 2013.

${ }^{7}$ Kim, M. Y., Hayat, M. J., Feiveson, A. H., and Cucinotta, F. A., "Prediction of Frequency and Exposure Level of Solar Particle Events," Health Physics, Vol. 9, 2009, pp. 68-81.

${ }^{8}$ Xapsos, M. A., Barth, J. L., Stassinopoulos, E. G., Burke, E. A., and Gee, G. B., "Space Environmental Effects: Model for Emission of Solar Protons (ESP) - Cumulative and Worst-Case Event Fluences," NASA TP-1999-209763, 1999.

${ }^{9}$ NASA Space Flight Human System Standard, Volume 1: Crew Health, NASA-STD-3001, 2007.

${ }^{10}$ Cucinotta, F. A., Kim, M. Y., Chappell, L. J., and Huff, J. L., "How Safe Is Safe Enough? Radiation Risk for a Human Mission to Mars," PLoS One, Vol. 8: 10, e74988, 2013a.

${ }^{11}$ Cucinotta, F. A., Kim, M. Y., and Chappell, L. J., Space Radiation Cancer Risk Projections and Uncertainties - 2012, NASA TP-2013-217375, 2013b.

${ }^{12}$ Wilson, J. W., et al., "HZETRN: Description of a Free-Space Ion and Nucleon Transport and Shielding Computer Program," NASA TP-3495, 1995.

${ }^{13}$ Slaba, T. C., Blattnig, S. R., and Badavi, F. F., "Faster and more Accurate Transport Procedures for HZETRN," Journal of Computational Physics, Vol. 229, 2010a, pp. 9397-9417.

${ }^{14}$ Singleterry, R. C., et al., "OLTARIS: On-Line Tool for the Assessment of Radiation in Space," Acta Astronautica, Vol. 68, 2011, pp. 1086-1097.

${ }^{15}$ SmartAssembly: http://www.sigmaxim.com/Products/SmartAssembly/smartassembly.html, Accessed June 2014.

${ }^{16}$ Slaba, T. C, Qualls, G. D., Clowdsley, M. S., Blattnig, S. R., Simonsen, L. C., Walker, S. A., and Singleterry, R. C., "Analysis of Mass Averaged Tissue Doses in CAM, CAF, MAX, and FAX.” NASA TP-2009-215562, 2009.

${ }^{17}$ Slaba, T. C, Qualls, G. D., Clowdsley, M. S., Blattnig, S. R., Walker, S. A., and Simonsen, L. C., "Utilization of CAM, CAF, MAX, and FAX for space radiation analyses using HZETRN," Advances in Space Research, Volume 45, 2010b, pp 866883.

${ }^{18}$ Kramer, R., et al., "All about FAX: A Female Adult Voxel Phantom for Monte Carlo Calculations in Radiation Protection Dosimetry," Physics in Medicine and Biology, Vol. 49, 2004, pp. 5203-5216.

${ }^{19}$ Hart, S. G., \& Staveland, L. E., "Development of NASA-TLX (Task Load Index): Results of empirical and theoretical research", In P. A. Hancock \& N. Meshkati (Eds.), Human Mental Workload: Advances in Psychology (pp. 139-183). Amsterdam, The Netherlands, 1988.

\section{Appendix: Habitat Module Assumptions}

\section{CLS (Node 2) Assumptions (4 crew)}

Updated 12/1/2012

\begin{tabular}{|c|c|c|}
\hline$\bullet$ & 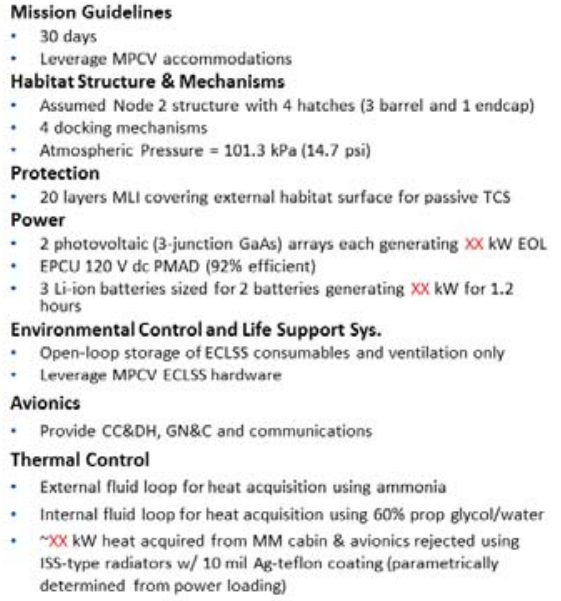 & $\begin{array}{l}\text { Crew Accommodations } \\
\text { - Standard suite for } 0 \text {-31 day orbital vehicle (ref. Human } \\
\text { Spaceflight Mission Analysis \& Design) } \\
\text {. Food, other crew items, sink(spigot), vacuum, laptop, } \\
\text { hand tools \& accessories, test equipment, photography } \\
\text { equipment, } \\
\text { Maintenance and Spares } \\
\text { - No Maintenance and Spares items } \\
\text { Science } \\
\text { - } 500 \text { kg pressurized science }(1.57 \mathrm{~m} 3,1 \mathrm{~kW}) \\
\text { - Unpressurized science payloads ignored } \\
\text { EVA } \\
\text { - Carries } 2 \text { suits and consumables for } 6 \times 2 \text { crew } 8 \text { hour } \\
\text { EVAs } \\
\text { Reserves } \\
\text { - Margin growth Allocation - } 20 \% \text { of basic mass } \\
\text {. Project Manager's Reserve - } 10 \% \text { of basic mass }\end{array}$ \\
\hline
\end{tabular}




\title{
Augmentation Module (MPLM) Assumptions (4 crew)
}

\author{
Updated 12/1/2012
}

- Mission Guidelines

180 days

Augmentation Module supports all attached vehicles during 180 day stay

- Habitat Structure \& Mechanisms

Assumed MPLM structure with 4 hatches ( 3 barrel and 1 endcap) 1 docking mechanisms

- $1 \times 0.5 \mathrm{~m}$ windows

Atmospheric Pressure $=101.3 \mathrm{kPa}(14.7 \mathrm{psi})$

- Protection

- 20 layers MLI covering external habitat surface for passive ICS

- Power

. 2 photovoltaic (3-junction GaAs) arrays each generating XX kW EOL

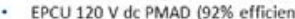

3 Li-ion batteries sized for 2 batteries generating XX kW for 1.2

- Environmental Control and Life Support Sys.

- $20 \%$ mass for redundant components on critical ECLSS subsystems

- 30 days open loop contingency consumables for critical subsystems

- Avionics

- Provide CC\&DH, GN\&C and communications

- Thermal Control

- External fluid loop for heat acquisition using ammoni

- Internal fluid loop for heat acquisition using $60 \%$ prop glycol/water

- XX kW heat acquired from MM cabin \& avionics rejected using

ISS-type radiators w/ 10 mil Ag-teflon coating (parametrically

determined from power loading)
- Crew Accommodations

- Custom suite for 180 day deep space transfer (ref. Human Spaceflight Mission Analysis \& Design)

Food, other crew items, sink(spigot), freezer, microwave oven, hand/mouth wash faucet, vacuum, laptop, trash compactor, printer, hand tools \& accessories, test equipment, photography equipment, exercise equipment, treadmill

- 4 ISS Rack-based Crew Quarters

- Maintenance and Spares

- Assume $1000 \mathrm{~kg}$ fixed and $500 \mathrm{~kg}$ each additional year with a $250 \mathrm{~kg} / \mathrm{m}^{3}$ density

- Science

- $500 \mathrm{~kg}$ pressurized science $(1.57 \mathrm{~m} 3,1 \mathrm{~kW}$

Unpressurized science payloads ignored

- EVA

- Carries consumables for $6 \times 2$ crew 8 hour EVAs

- Reserves

- Margin growth Allocation - $20 \%$ of basic mass

- Project Manager's Reserve - $10 \%$ of basic mas 